\title{
Polarization dependent a-factor in InGaAs/InGaAsP MQW material
}

\author{
Sørensen, M.; Storkfelt, Niels; Jepsen, Kim Stokholm; Mikkelsen, Benny; Stubkjær, Kristian
}

Published in:

Proceedings of the 13th IEEE International Semiconductor Laser Conference

Publication date:

1992

Document Version

Publisher's PDF, also known as Version of record

Link back to DTU Orbit

Citation (APA):

Sørensen, M., Storkfelt, N., Jepsen, K. S., Mikkelsen, B., \& Stubkjær, K. (1992). Polarization dependent a-factor in InGaAs/InGaAsP MQW material. In Proceedings of the 13th IEEE International Semiconductor Laser Conference (pp. 62-63). IEEE.

\section{General rights}

Copyright and moral rights for the publications made accessible in the public portal are retained by the authors and/or other copyright owners and it is a condition of accessing publications that users recognise and abide by the legal requirements associated with these rights.

- Users may download and print one copy of any publication from the public portal for the purpose of private study or research.

- You may not further distribute the material or use it for any profit-making activity or commercial gain

- You may freely distribute the URL identifying the publication in the public portal

If you believe that this document breaches copyright please contact us providing details, and we will remove access to the work immediately and investigate your claim 


\title{
Polarization Dependent $\alpha$-Factor in InGaAs/InGaAsP MQW Material
}

\author{
M. Soerensen, N. Storkfelt, K.S. Jepsen, B. Mikkelsen and K.E. Stubkjaer \\ Center for Broadband Telecommunications, Electromagnetics Institute \\ Technical University of Denmark, Building 348, DK-2800 Lyngby, Denmark
}

Introduction: Multiple Quantum Well (MQW) structures are of high interest for many types of optical devices because of the improved performance. Material parameters such as the linewidth enhancement factor ( $\alpha$-factor) [1] and the related differential gain $(d g / d N)$ and differential refractive index $(d n / d N)$ are essential in the design of lasers and optical amplifiers, because they govern important properties as linewidth, frequency response and resonance frequency. So far, most of the characterization has been carried out for the TE-polarization, but the polarization dependence of these parameters is important to the optimization of the MQW structures.

Here we present measurements of the polarization dependence of $d n / d N, d g / d N$ and the $\alpha$-factor in a MQW amplifier. Theoretical results are also presented and reasonable agreement with measured data is obtained.

Measurements: The experiments are performed on a four-well MQW DC-PBH [2] amplifier with gain peak wavelengths of 1532 and $1500 \mathrm{~nm}$ for the TEand TM-polarization, respectively. The InGaAs well layers and the InGaAsP barrier layers are 80 and $130 \AA$ thick, respectively, as shown in the band diagram in Fig. 1. The guide layers are each $1000 \AA$ thick and of the same composition as the barriers. The active stripe is $2.0 \mu \mathrm{m}$ wide and $800 \mu \mathrm{m}$ long. The facets are AR-coated giving residual reflectivities of approximately $10^{-3}$.

Measurements of $d n / d N, d g / d N$ and the $\alpha$ - factor are performed with a dynamic selfheterodyne method [3],[4], and the calculations are performed using a detailed model [5]. The TE-and TMpolarizations are considered at the respective gain peaks.

Discussion: Fig. 2 shows measured and calculated $d n / d N$ vs. injection current for the two polarizations. At low injection currents $d n / d N$ is significantly smaller for the TM-polarization, which can be explained as follows: Free carriers normally contribute to $d n / d N$, because of collision and relaxation processes (free carrier plasma effect). However, in a quantum well the carriers are not free to move in the direction perpendicular to the well, and therefore will not contribute to $d n / d N$ for TM-polarized light. For high injection currents, the difference in $d n / d N$ between the two polarizations becomes negligible. This is not in accordance with the theoretical predicted difference, which is mainly due to the plasma effect, and nearly independent of the injection level (carrier density). However, carrier overflow [4],[6] is not included in the calculations. This could explain our experimental data, since carriers leaking into the barrier states will contribute to the plasma effect even for the TM-polarization, thus reducing the $d n / d N$ difference at higher injection currents. Figure 3 shows the measured and calculated values for $d g / d N$ vs. the injection current for the TE- and TM-polarizations. The measured $d g / d N$ is smaller for the TM-polarization at low injection, but are identical for the two polarizations at high injection levels. Contrary to this, the theoretical results show higher values of $d g / d N$ for the TM polarization. The theoretical predictions are considerably larger than the measured values. A better agreement might be achieved by including carrier overflow in the model. This would tend to saturate the predicted gain at high injection currents, since: the carriers in the barrier states do not contribute to the gain. The measured and theoretically predicted results for the $\alpha$-factor vs. injection current are shown in Fig. 4. It is worth noting, that in spite o: the smaller measured values of $d g / d N$ at low injertion for the TM-polarization there is no difference in the $\alpha$-factors due to the absence of the plasma effect for the TM polarization. Fig. 5 shows the measured $\alpha$-factor vs. single pass gain for the two polarizations. As the $\alpha$-factor for a given gain is larger for the TM-polarization an improvement of the linewidth for a MQW laser oscillating in TM-mode is not irnmediately expected. However, the application of tensile strained layer MQW, which increases the TM gain above the TE gain, might change this, since the plasma effect would still be absent for the TMpolarization. Low $\alpha$-factors in tensile strained MLW material has in fact been reported in in [8]. 
Conclusion: The polarization dependence of the $\alpha$ factor has been investigated for unstrained MQW material. Experimentally the $\alpha$-factor has been found to be smaller for TE compared to TMpolarization at a given gain. However, it has been pointed out that the contribution from the free carrier plasma effect to the refractive index is negligible for TM-polarized light at low injection levels. This

\section{References}

[1] C. Henry: J. Quantum Electronics Feb. 1982, pp. 259-264.

[2] H. Asano et al: In proc. of OFC'91, paper WG1.

[3] N. Storkfelt et al.: Photon. Technol. Lett., July 1991, pp. 632-634.

[4] M. Yamaguchi et al.: In proc. of ECOC'91, paper TuA3-2.

[5] K.S.Jepsen et al., accepted for publ. in Photon. Technol. Lett., June 1992.

[6] W.F.Sharfin et al.: In proc. of ECOC'91, paper TuA4-4.

[7] J.Lee et al.: J. Quantum Electronics, March 1992, pp. 624-634

[8] P.Thijs et al.: J. Quantum Electronics, June 1991, pp. 1426-1439.

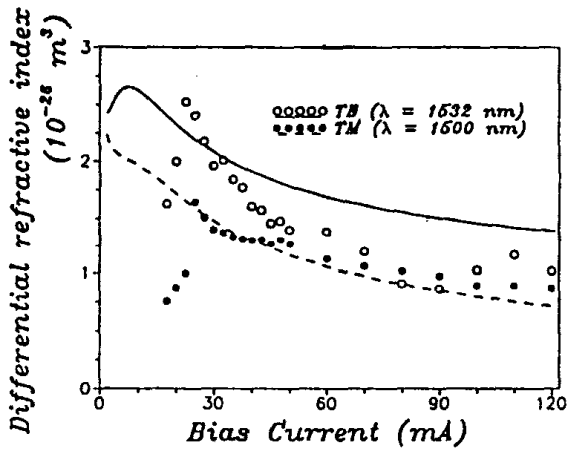

Figure 2: Differential refractive index $d n / d N$ vs. injection current. The lines are calculated.

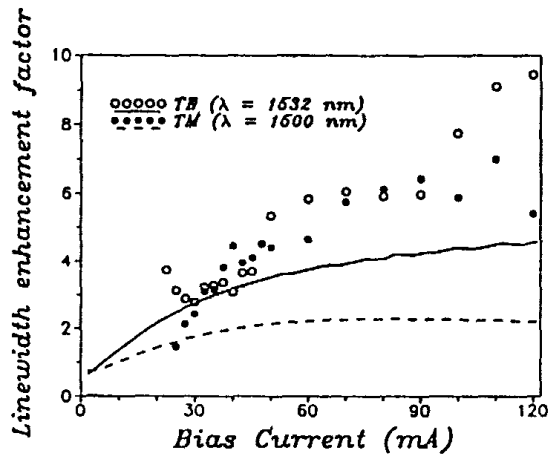

Figure 4: $\alpha$-factor vs. injection current. The lines are calculated. leads to a significant reduction in $d n / d N$ compared to the TE-polarization and is important in relation to strained MQW lasers. These can be made to oscillate in the TM-mode with potential reduction of the $\alpha$-factor.

Acknowledgement: The authors would like to thank Dr. M. Yamaguchi, NEC for supplying the amplifiers.
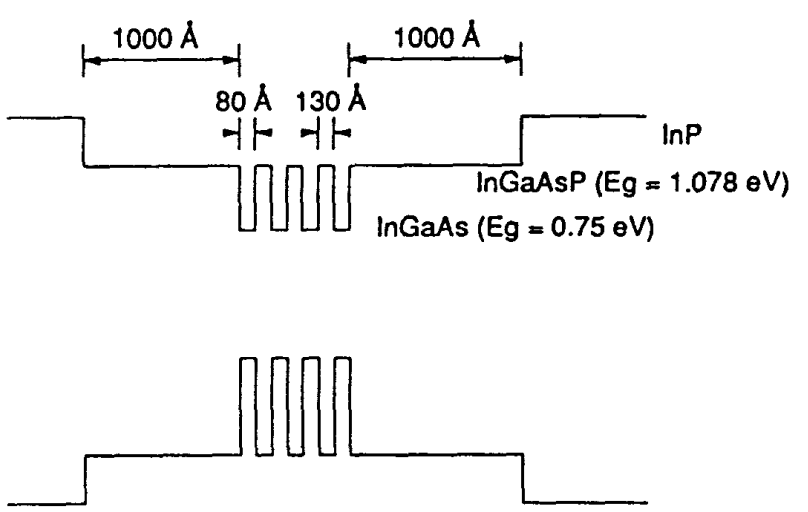

Figure 1: Energy band diagram of the MQW amplifier.

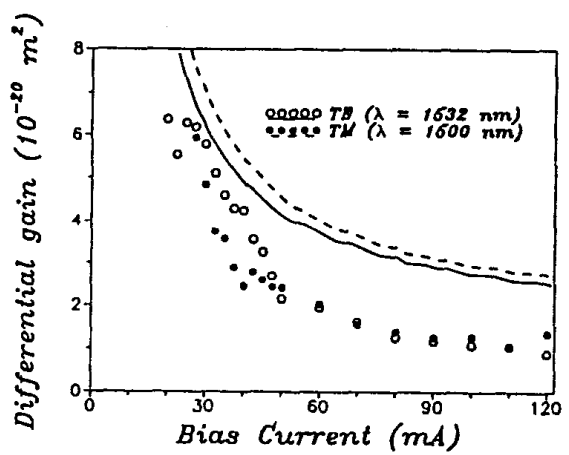

Figure 3: Differential gain $d g / d N$ vs. injection current. The lines are calculated.

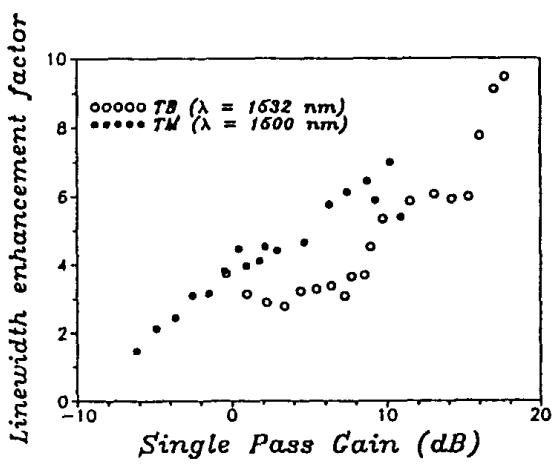

Figure 5: $\alpha$-factor vs. single-pass gain. 